\title{
SIMULTANEOUS CARBON AND NUTRIENT REMOVAL FROM DAIRY WASTEWATER IN SEQUENCING BATCH REACTOR (SBR)
}

\author{
PANNIRSELVAM R. ${ }^{1{ }^{*}}$ \\ IBRAHIM Y. ${ }^{2}$ \\ NAVANEETHA GOPALAKRISHNAN A. ${ }^{3}$
}

\author{
${ }^{1}$ Centre for Environmental Studies \\ Anna University, Chennai - 600 025, India \\ ${ }^{2}$ Cresant Engineering College, Chennai, India \\ ${ }^{3}$ Head of Department of Civil Engineering \\ Tagore Engineering College, Chennai -600 127, India
}

*to whom all correspondence should be addressed:

e-mail:spgspannir@gmail.com
Received: 02/05/2015

Accepted: 05/08/2015

Available online: $28 / 08 / 2015$

\section{ABSTRACT}

Sequencing batch reactor (SBR) is a time-oriented wastewater treatment (WWT) system in a single reactor with flow and energy input according to the predetermined operational cycle time. The treatment efficiency of SBR varies with the duration of the cycle time, which affects the reactor size and hence the cost of WWT plant. This paper presents an experimental study in a bench scale SBR model with a working volume of $15 \mathrm{~L}$ with an onjective to determine the optimum cycle time for simultaneous removal of carbon and nutrient from the dairy wastewater. Using the equalized dairy wastewater experiments with four cycle times of $8 \mathrm{~h}, 6 \mathrm{~h}, 4 \mathrm{~h}$ and $2 \mathrm{~h}$ were conducted and the effluent concentrations were compared to the effluent standards. In conclusion, the data suggest the SBR process with $6 \mathrm{~h}$ cycle time as the optimum cycle time for treating dairy wastewater for simultaneous carbon and nutrient removal.

Key words: anoxic process, cycle time, denitrification, effluent standards, nitrification, sequencing batch reactor, wastewater treatment.

\section{Introduction}

The objective of this study is to determine the optimum cycle time in sequencing batch reactor (SBR) for simultaneous removal of carbon and nutrient from the dairy wastewater. Dairies are producing one to three kilo liter $(\mathrm{kL})$ of wastewater per $\mathrm{kL}$ of milk processed and the wastewater is characterized by high chemical oxygen demand (COD) $\left(2500-4000 \mathrm{mg} \mathrm{l}^{-1}\right)$, bio-chemical oxygen demand (BOD) $\left(1300-2000 \mathrm{mg} \mathrm{I}^{-1}\right)$ and nutrients with a high intense foul odour. Dairy wastewater pollutes ecosystem and groundwater and results in eutrophication of surface water bodies. Morishita (1985) has reported that irrigation with nitrogen-enriched treated wastewater could result in reduced yield, increased susceptibility to pests and diseases and microbial growth in the soil with reduction of soil permeability and hydraulic conductivity. The need for nitrification in wastewater treatment (WWT) arises from water quality concerns over the effect of ammonia on receiving water with respect to dissolved oxygen (DO) concentration and fish toxicity, from the need to provide nitrogen removal to control eutrophication and in the control for water reuse application including groundwater recharge (Metcalf and Eddy, 2003). Dairy wastewater, therefore, requires adequate treatment for carbon and

Pannirselvam R., Ibrahim Y. and Navaneetha Gopalakrishnan A. (2015), Simultaneous carbon and nutrient removal from dairy wastewater in sequencing batch reactor (SBR), Global NEST Journal, 17(3), 628-636. 
nitrogen removal before disposal either on the land or in to the surface water body to meet the effluent standards prescribed by the Central Pollution Control Board (CPCB).

SBR, a variation of the activated sludge process (ASP) with batch process in a single reactor in which wastewater is added, aerated and settled to remove undesirable constituents and then the effluent decanted and discharged, is reported as a highly useful technology in the treatment of dairy wastewater (Norcross, 1992; Ketchun, 1997; Gutierrez et al., 2002; Kargi et al., 2003; Sirianuntapiboon et al., 2005; Mahvi, 2008). Conventional ASP Systems are space oriented; wastewater flows from one tank to another on continuous basis and virtually all tanks have a predetermined liquid volume. The SBR on the other hand is a time oriented system with pre determined flow, energy input and tank volume varying according to some predetermined, periodic operating strategy for different phases of the treatment process such as fill, react, settle and decant (Keller et al., 2001).

The biological removal of nitrogen from wastewater is carried out through a three-step process: (1) the conversion of ammonia from organic nitrogen by hydrolysis and microbial activities, called ammonification; (2) the aerobic conversion of ammonia to nitrate by reacting the ammonia with oxygen in a process called nitrification; and ( 3 ) the conversion of nitrate to nitrogen gas by reacting the nitrate with organic carbon under anoxic conditions in a process called denitrification (EPA, 2008). Biological nitrogen removal generally requires a sequence of anaerobic-anoxic-aerobic phases with multiple feeding events over one cycle (Puig et al., 2007). The presence of DO inhibits some desirable biological processes, particularly denitrification. DO concentrations of $0.2 \mathrm{mg} \mathrm{l}^{-1}$ or greater decrease the denitrification rate in the anoxic zone. This is because the energy spent in breaking $\mathrm{NO}_{3}$ to obtain oxygen is greater than that from using molecular oxygen, so most microorganisms preferentially use DO when it is available rather than $\mathrm{NO}_{3}$. Denitrification is made most efficient when DO is kept low throughout the anoxic zone (EPA, 2008).

Generally in ASP for nitrification and denitrification two separate basins, one for nitrification and another for denitrification are required. SBR has undergone several modifications to achieve nitrification and denitrification along with COD and phosphorus removal by creating the same macroscopic conditions in a single reactor to have simultaneous nitrification and denitrification (SNdN) (Pochanna \& Keller, 1999; David, 2001; Obaja et al., 2003; Zhang \& Zhaui-qi, 2007). The main advantage of SNdN in SBRs is the decrease in time required for carbon and nitrogen removal (Munch et al., 1996) and a single reactor for SNdN can make wastewater treatment feasible even for smaller flows that would have difficulties in dealing a multi-unit treatment train as in ASP (Roe et al., 1999). The SBR operating strategy must be based on a dynamic cycle definition in line with process efficiency. The carbon and nutrient removal efficiencies of in SBR vary with the duration of the cycle time and time for each phase of the process in a cycle of operation. The cycle time dictates the number of cycles per day, the volume of reactor required and the cost of the WWT system and is based on the strength of the wastewater (Coma et al., 2010).

A fundamental relationship between the cycle time, recycle ratio and the effective sludge age, is to be developed and used in the determination of physical design parameters (Artan etal 2002). The cycle time for weak domestic wastewater varies from 4 to $6 \mathrm{~h}$, while for industrial wastewater from 4 to $36 \mathrm{~h}$ depending on the strength of the wastewater (Artan \& Orhon, 2005). This paper presents an experimental study, carried out in a bench scale SBR model to test the suitability of SBR technology for SNdN from dairy wastewater using live effluent from a dairy WWT Plant in order to study the feasibility of removing nitrogenusing SBR process and to select optimum cycle time. Generally the laboratory studies are based on simulated synthetic wastewater. But in this study the live wastewater from the dairy without cold storage was used. Further this study is to assist the dairy to modify the existing WWT Plant based on extended aeration ASP, adopting process modification for SNdN of wastewater without investing large amount on capital expenditures for an additional units for Nitrogen removal. 
The objective of the experimental studies was to ascertain the suitability of SBR for simultaneous removal of carbon and nutrient from dairy wastewater and to select the optimum cycle time.

\section{Materials and Methods}

Experimental study was carried out at Aavin dairy, Sholinganallur, Chennai, India . At present the dairy is processing every day $250 \mathrm{~kL}$ of milk and generating $500 \mathrm{~kL}$ of wastewater and has a WWT plant in operation based on extended aeration activated sludge process (EA ASP). The concentrations of raw dairy wastewater and treated effluent, the treatment efficiency of the existing WWT plant and the effluent standards prescribed by the CPCB for discharging treated wastewater on land are furnished in Table 1.

Table 1. Concentrations of raw and treated dairy wastewater, efficiency of the existing WWT Plant and the effluent standards

\begin{tabular}{cccccc}
\hline S.No. & Parameters & $\begin{array}{c}\text { Raw } \\
\text { wastewater } \\
\text { concentrati } \\
\text { on }\end{array}$ & $\begin{array}{c}\text { Treated effluent } \\
\text { Concentration }\end{array}$ & $\begin{array}{c}\text { Treatment } \\
\text { efficiency of } \\
\text { WWT Plant, } \\
\text { (\%) }\end{array}$ & $\begin{array}{c}\text { Effluent } \\
\text { Standards for } \\
\text { discharge on } \\
\text { land (CPCB) }\end{array}$ \\
\hline 1 & pH & 8.5 & 7.1 & & $5.5-9.0$ \\
2 & COD & 3350 & 240 & 92.8 & 250 \\
3 & BOD & 1700 & 26 & 98.5 & 30 \\
4 & TSS & 1150 & 91 & 92.1 & 150 \\
5 & Oil \& Grease & 135 & 8 & 94.1 & 10 \\
6 & Total Kjeldahl Nitrogen (TKN) & 140 & 75 & 46.5 & 100 \\
7 & Ammonical Nitrogen & 125 & 68 & 45.6 & 50 \\
8 & (NH $\left.{ }_{3}-\mathrm{N}\right)$ & & & & \\
9 & Total Phosphorus (TP) & 55 & 28 & 49.1 & 5.0 \\
\hline
\end{tabular}

Note: All parameters except $\mathrm{pH}$ are expressed in $\mathrm{mg} \mathrm{I}^{-1}$

From Table 1 it could be seen that the effluent from the existing WWT Plant is not satisfying the effluent standards in respect of Total Kjeldahl Nitrogen (TKN), Ammonia- nitrogen $\left(\mathrm{NH}_{3}-\mathrm{N}\right)$, Nitrate-nitrogen $\left(\mathrm{NO}_{3}-\mathrm{N}\right)$ and Total Phosphorous (TP) and the nutrient removal efficiency of the WWT Plant is very low. The experimental bench scale SBR model of $25 \mathrm{~cm}$ length, $20 \mathrm{~cm}$ width and $35 \mathrm{~cm}$ depth with a working volume of $15 \mathrm{~L}$ was fabricated of polymetacrylate and used in this study to ascertain the suitability of SBR for SNdN from dairy wastewater and to select the optimum cycle time. The SBR model was fitted with a blower to supply air, a control knob to regulate air flow and diffuser stone at the bottom of the reactor to provide fine bubble aeration. The photographic view of SBR model and details of arrangements are shown in Fig. 1 and 2 respectively.

The SBR model was first acclimatized to increase the mixed liquor suspended solids (MLSS) concentration, for which the reactor was initially filled with seed sludge collected from the secondary clarifier of the existing WWT Plant mixed with raw dairy wastewater and aerated for $24 \mathrm{~h}$. At the end of first $24 \mathrm{~h}, 10 \%$ of the supernatant was decanted and replaced with equal amount of raw dairy wastewater and again aerated for another $24 \mathrm{~h}$. At the end of second $24 \mathrm{~h}, 20 \%$ of the supernatant was decanted and replaced with equal amount of raw dairy wastewater and again aerated for $24 \mathrm{~h}$. At the end of third $24 \mathrm{~h}, 30 \%$ of the supernatant was decanted and replaced with equal amount of raw dairy wastewater and again aerated for $24 \mathrm{~h}$. At the end of third day the sludge was acclimatized to steady state MLSS concentration of $4000 \mathrm{mg} \mathrm{l}^{-1}$.

In general, the denitrification rate increases with increasing internal recirculation, up to a maximum of 500 percent. Denitrification in wastewaters with BOD- to-TKN ratios less than 4:1 or COD-to-TKN ratios less than 
10:1 typically is not benefited by high internal recirculation. This is because such wastewater has insufficient carbon to support an elevated denitrification rate. Having two anoxic zones allows lower TKN effluent concentrations to be achieved because more of the nitrates produced after nitrification in the aeration basin can be treated by flowing through the second anoxic zone (EPA, 2008). BOD- to-TKN ratio of the dairy wastewater used in the study is 12:1 and COD-to-TKN ratio is 24:1 and hence an additional anoxic phase was provided in addition to anoxic fill within a cycle (prior to settling) to minimize effluent nitrates.

The economics of WWTP based on SBR technology depends on the optimum cycle time and hence considering the strength of the wastewater four cycle times of $2 \mathrm{~h}, 4 \mathrm{~h}, 6 \mathrm{~h}$ and $8 \mathrm{~h}$ were considered. The experiments were carried out in the SBR model for the four cycle times involving five phases of anoxic fill, aerobic reaction, anoxic reaction, settling and decanting at the specified duration for each phase as detailed in Table 2 . The equalized wastewater from the dairy was used as feed wastewater to the reactor in this study. During anoxic fill and anoxic reaction the aeration was switched off and the liquor was stirred with a mechanical stirrer at a speed of 30 to $40 \mathrm{rpm}$. The MLSS concentration in the reactor during aerobic reaction phase was maintained at about $4000 \mathrm{mg} \mathrm{l}^{-1}$. In all the experiments for different cycle times the fill flow was maintained at the rate of $0.375 \mathrm{~L} \mathrm{~min}^{-1}$. After anoxic filling, aeration was carried out for the specified time, followed by a short anoxic react period to facilitate denitrification to take place. Then the mixed liquor was allowed to settle for the specied time and the supernatant was decanted using a small hand operated suction pump by operating slowly for the specified time to avoid drawal of solids. Excess sludge formed was wasted after the treated effluent was decanted and before the next fill. The next cycle was started following the different phases of the process.

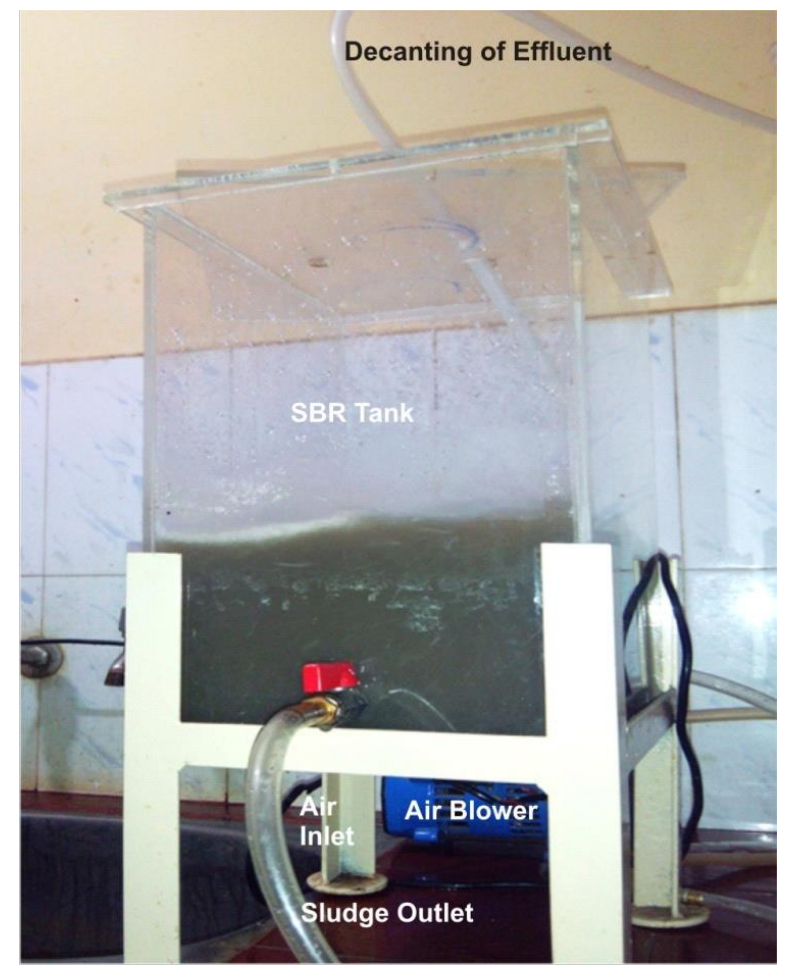

Figure 1. Photographic view of Experimental set up 


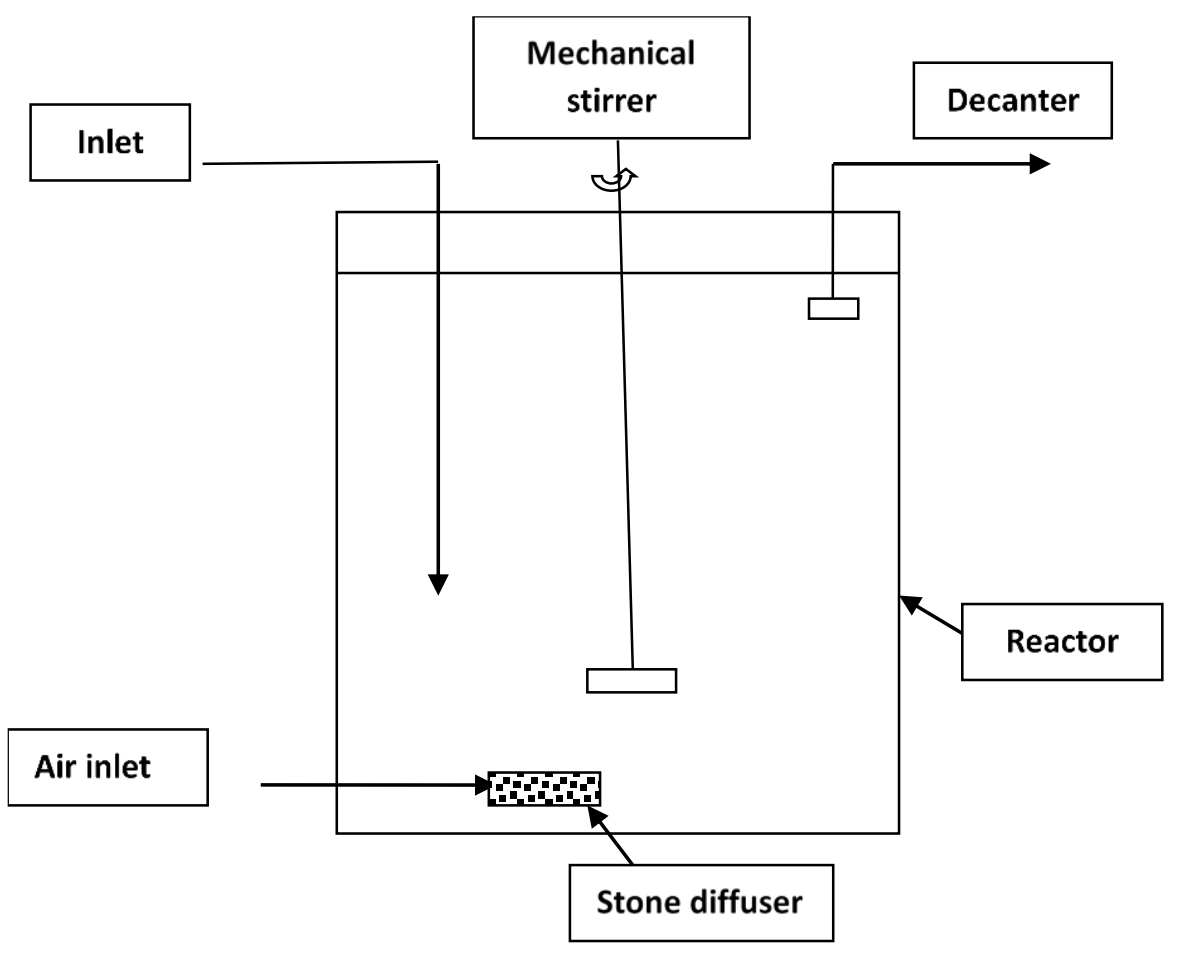

Figure 2. Experimental setup

Table 2. Cycle times and durations for different phases of the experiments for SBR process

\begin{tabular}{|c|c|c|c|c|c|c|c|c|}
\hline \multirow{2}{*}{$\begin{array}{c}\text { Experiment } \\
\text { No. }\end{array}$} & \multirow{2}{*}{$\begin{array}{l}\text { Total } \\
\text { cycle } \\
\text { time, h }\end{array}$} & \multicolumn{5}{|c|}{ Duration for the phase, $\min$} & \multirow{2}{*}{$\begin{array}{c}\text { No. of } \\
\text { Batches per } \\
\text { day }\end{array}$} & \multirow{2}{*}{$\begin{array}{l}\text { Volume of } \\
\text { liquid in the } \\
\text { reactor, L }\end{array}$} \\
\hline & & $\begin{array}{l}\text { Anoxic } \\
\text { Fill }\end{array}$ & Aeration & $\begin{array}{r}\text { Anoxic } \\
\text { react }\end{array}$ & Settling & Decanting & & \\
\hline 1 & 8 & 40 & 280 & 20 & 60 & 20 & 3 & 15 \\
\hline 2 & 6 & 30 & 255 & 15 & 45 & 15 & 4 & 9.75 \\
\hline 3 & 4 & 20 & 170 & 10 & 30 & 10 & 6 & 7.5 \\
\hline 4 & 2 & 10 & 85 & 5 & 15 & 5 & 12 & 3.75 \\
\hline
\end{tabular}

In the model SBR two experiments each with $8 \mathrm{~h}$ and $6 \mathrm{~h}$ cycle times, four experiments each with $4 \mathrm{~h}$ and $2 \mathrm{~h}$ cycle times were conducted. The effluent from the SBR model from each experiment was sampled and analysed for the concentrations of parameters such as $\mathrm{pH}, \mathrm{COD}, \mathrm{BOD}$, TSS, Oil and Greases, TKN, $\mathrm{NH}_{3}-\mathrm{N}, \mathrm{NO}_{3}-$ $\mathrm{N}$ and TP using the methods specified in the Standard method for examination of water and wastewater (APHA 1998) and as listed in Table 3.

Table 3. Methods used for the analysis of the characteristics of the effluent

\begin{tabular}{cl}
\hline Parameter & \multicolumn{1}{c}{ Method used for analysis of the parameter } \\
\hline $\mathrm{pH}$ & Electrometric method using $\mathrm{pH}$ meter. \\
$\mathrm{COD}$ & Dichromate digestion using open reflux method \\
$\mathrm{BOD}, \mathrm{DO}$ & Winkler's method to measure DO \\
$\mathrm{TSS}, \mathrm{MLSS}$ & Gravimetric method \\
$\mathrm{Oil} \&$ grease & Trichloror-trifluoroethane extraction method \\
$\mathrm{TKN}$ & Kjeldahl method using Kjeldahl flask. \\
$\mathrm{NH}_{3}-\mathrm{N}$ & Titrimetric method \\
$\mathrm{NO}_{3}-\mathrm{N}$ & spectrophotometric method \\
$\mathrm{TP}$ & Stannous chloride method \\
\hline
\end{tabular}


The data on the concentrations of the effluent in respect of different parameters for different cycle times were compared to the effluent standards to ascertain the compliance of the standards. The data of the effluent concentrations were expressed as mean, \pm standard deviation based on two to four experiments and presented as bar charts. Further the percent removal efficiencies of the SBR model for different parameters in the experiments for different cycle times and percent increase in removal efficiencies for increase in cycle time were also worked out to ascertain the optimum cycle time.

\section{Results and Discussion}

The objectives of the study were to explore the feasibility of simultaneous removal of carbon and nutrients in SBR from dairy wastewater and to facilitate the Aavin dairy to install a cost effective new WWT Plant to fulfill the legal requirement by replacing the existing WWT Plant based on Extended Aeration ASP technology. The study was carried out at the dairy premises using the actual wastewater from the dairy unlike such studies usually carried out with simulated synthetic wastewater.

The bench scale SBR model was fabricated with 15 I working volume and provided with aeration facility with flow control and timer facility to create aerobic and anoxic conditions. The important requirement of SBR process is the acclimation of the biomass to exhibit stable nitrification and good settling characteristics before commissioning the process. In an experimental study in a bench scale SBR model with $8 \mathrm{~L}$ working volume to treat tannery wastewater it took 45 days for acclimation (Ganesh et al., 2006). In this study to treat dairy wastewater in a bench scale SBR model it took only three days to acclimation due to the typical characteristics of the dairy wastewater.

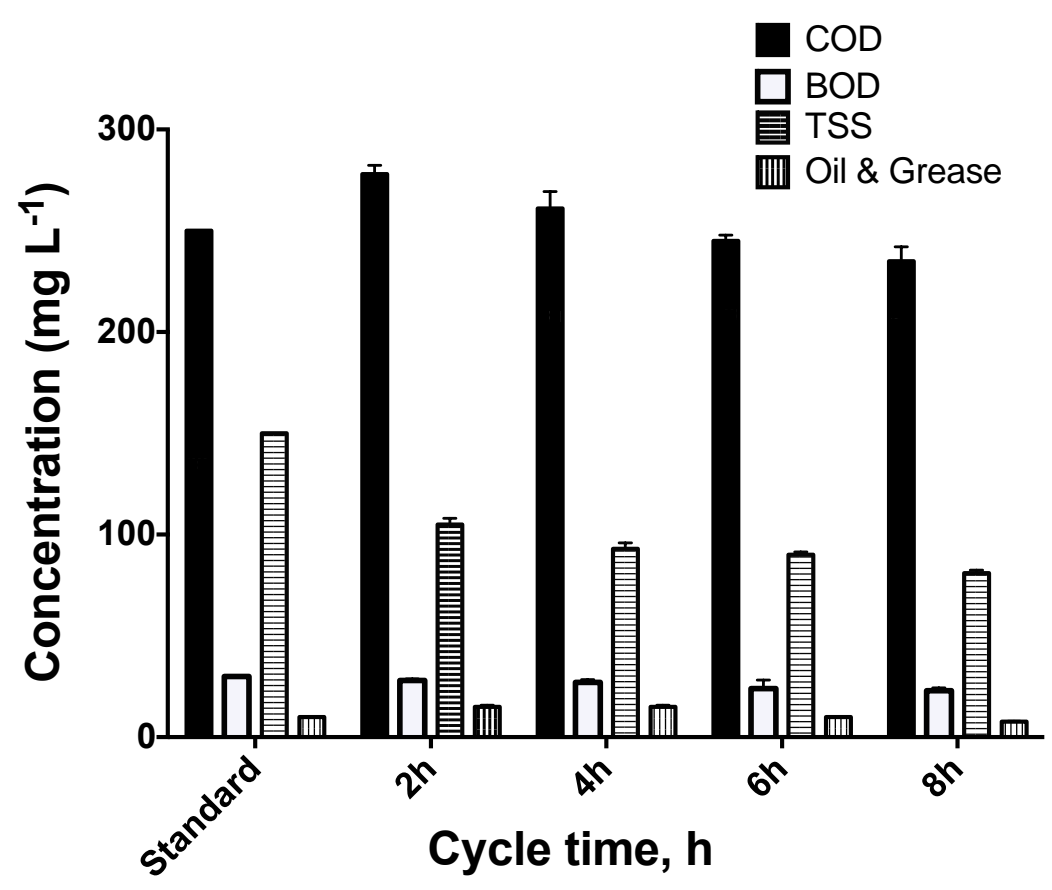

Figure 3. Performances of SBR of different cycle times for carbon removal

The comparison of mean values \pm standard deviation (SD) of the concentrations of the effluents from experiments of different cycle times with effluent standards is presented in Table 4 and Fig 3 and 4. 
Table 4. Relative concentrations of effluent of different cycle times of the SBR process

\begin{tabular}{|c|c|c|c|c|c|}
\hline \multirow[b]{2}{*}{ Parameters } & \multicolumn{4}{|c|}{ Concentrations of effluent (mean \pm SD) } & \multirow[b]{2}{*}{$\begin{array}{c}\text { Effluent } \\
\text { standard }\end{array}$} \\
\hline & $\begin{array}{c}8 \mathrm{~h} \text { cycle } \\
\text { time }\end{array}$ & $\begin{array}{c}6 \mathrm{~h} \text { cycle } \\
\text { time }\end{array}$ & $\begin{array}{c}4 \mathrm{~h} \text { cycle } \\
\text { time }\end{array}$ & $\begin{array}{c}2 \text { h cycle } \\
\text { time }\end{array}$ & \\
\hline $\mathrm{pH}$ & $7.2 \pm 0$ & $7.2 \pm 0$ & $7.1 \pm 0$ & $7.1 \pm 0$ & $5.5-9.0$ \\
\hline COD & $235 \pm 7.07$ & $245 \pm 2.83$ & $261 \pm 8.28$ & $278 \pm 4.24$ & 250 \\
\hline BOD & $23 \pm 1.41$ & $24 \pm 4.24$ & $27 \pm 1.41$ & $28 \pm 0.82$ & 30 \\
\hline TSS & $81 \pm 1.41$ & $90 \pm 1.41$ & $93 \pm 2.94$ & $105 \pm 3.0$ & 150 \\
\hline Oil \& Grease & $7.7 \pm 0.14$ & $10 \pm 0.28$ & $15 \pm 0.82$ & $15 \pm 0.82$ & 10 \\
\hline TKN & $18 \pm 0$ & $24 \pm 0$ & $37 \pm 1.26$ & $52 \pm 1.26$ & 100 \\
\hline $\mathrm{NH}_{3}-\mathrm{N}$ & $16 \pm 0$ & $23 \pm 0$ & $35 \pm 0.5$ & $38 \pm 0.82$ & 50 \\
\hline TP & $3 \pm 0$ & $5 \pm 0$ & $7 \pm 0$ & $8 \pm 1.41$ & 5 \\
\hline $\mathrm{NO}_{3}-\mathrm{N}$ & $1 \pm 0$ & $3 \pm 0$ & $7 \pm 0.08$ & $11 \pm 0.82$ & 10 \\
\hline
\end{tabular}

Note: All parameters except $\mathrm{pH}$ are expressed in $\mathrm{mg} \mathrm{I}^{-1}$

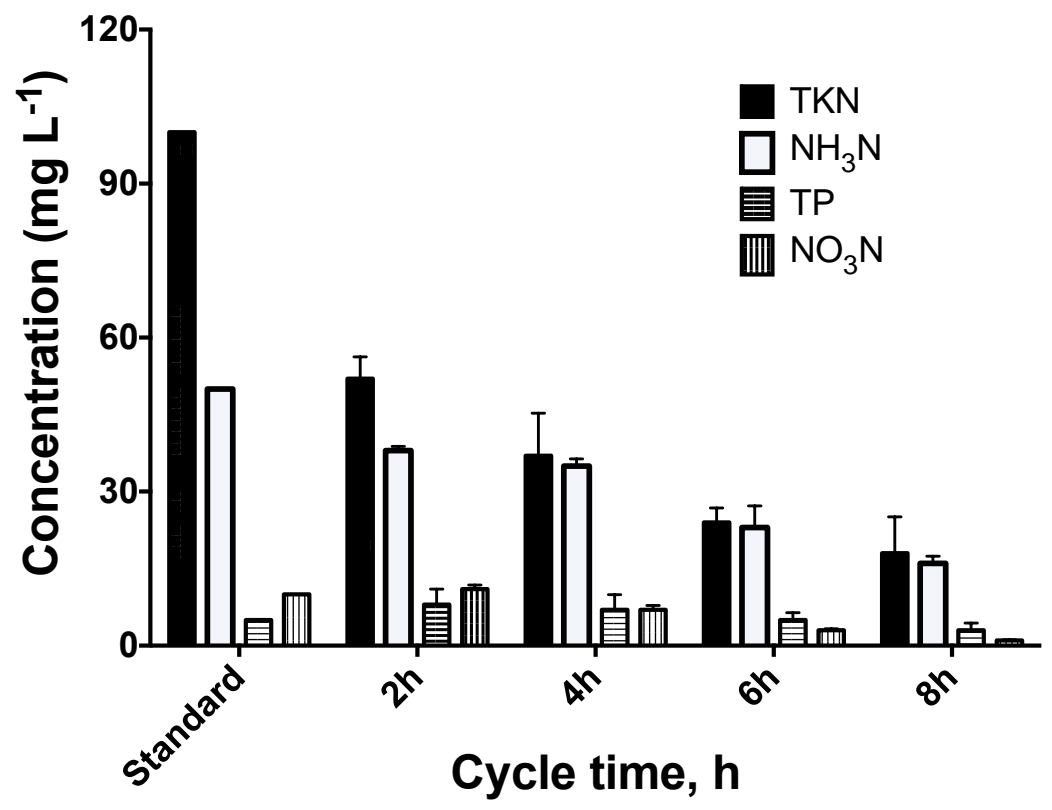

Figure 4. Performances of SBR for different cycle times for nutrient removal

In the existing WWT Plant the removal efficiencies of COD, TKN, $\mathrm{NH}_{3}-\mathrm{N}$ and TP were 92.8, 46.5, 45.6 and 49.1\% respectively with concentrations of TKN, $\mathrm{NH}_{3}-\mathrm{N}, \mathrm{TP}$ and $\mathrm{NO}_{3}-\mathrm{N}$ in the effluent were 75, 68, 28 and $12 \mathrm{mg} \mathrm{I}^{-1}$ against the standard of $100,50,5$ and $10 \mathrm{mg} \mathrm{l}^{-1}$ respectively. Hence the nutrient removal with simultaneous nitrification and denitrification ( $\mathrm{SNdN}$ ) were found necessary. The denitrification is generally increased when COD to TKN ratio of the feed wastewater is more than 10:1. In most of the wastewater COD is to be added to increase the COD to TKN ratio (EPA 2008). But in the dairy wastewater under study the COD to TKN ratio was 24:1 and hence no addition of COD was needed. Further providing second anoxic zone after aeration was found beneficial to lower TKN concentration in the effluent. In conventional WWT Plant with ASP technology anoxic zones are generally provided in separate basins and wastewater is pumped between the basins (Metcalf \& Eddy, 2003). But in the model SBR anoxic condition was created in the same basin by switching off the aeration. So in the SBR for SNdN no energy was required for pumping wastewater between the basins as the anoxic condition was created in the same basin and energy would be saved. Though several research 
findings have been reported on SBR for dairy Effluent treatment plant, no study on SNdN using dairy effluent using SBR was reported.

In a study by Debik and Manav (2010) on biological removal of nutrient from the domestic wastewater in SBR, four different cycle times were used and $8 \mathrm{~h}$ cycle time was found to be optimum and removal efficiencies of COD, TKN, $\mathrm{NH}_{3}-\mathrm{N}$ and TP were reported to be $91,78,85$ and $87 \%$ respectively. Obaja et al., (2003) tested $4 \mathrm{~h}$, $8 \mathrm{~h}, 12 \mathrm{~h}$, and $24 \mathrm{~h}$ cycle time in SBR for treating piggery wastewater and found that the best nitrification was obtained in $4 \mathrm{~h}$ cycle time. In this study out of the experiments with four cycle times of $2 \mathrm{~h}, 4 \mathrm{~h}, 6 \mathrm{~h}$ and $8 \mathrm{~h}$, only experiments with $6 \mathrm{~h}$ and $8 \mathrm{~h}$ cycle times the design objectives were met and produced effluents satisfying the effluent standards with effluent concentrations and removal efficiencies of COD, TKN, NH ${ }_{3}-\mathrm{N}, T P$ and $\mathrm{NO}_{3}-\mathrm{N}$ as $245 \mathrm{mg} \mathrm{l}^{-1}$ (93.7\%), $24 \mathrm{mg} \mathrm{l}^{-1}(82.9 \%), 23 \mathrm{mg} \mathrm{l}^{-1}(81.6 \%), 5 \mathrm{mg} \mathrm{l}^{-1}$ (90.9) and $3 \mathrm{mg} \mathrm{l}^{-1}(83.3 \%)$ and $235 \mathrm{mg} \mathrm{l}^{-1}(93 \%), 18 \mathrm{mg} \mathrm{l}^{-1}(87.1 \%), 16 \mathrm{mg} \mathrm{l}^{-1}(87.2 \%)$ and $1 \mathrm{mg} \mathrm{l}^{-1}(94.4 \%)$ respectively for $6 \mathrm{~h}$ and $8 \mathrm{~h}$ cycle times. The performance of this study is comparable to the earlier study by Obaja et al., on piggery wastewater and showed better performance than the earlier study on domestic wastewater by Debik and Manav.

The removal efficiencies of $\mathrm{COD}, \mathrm{TKN}, \mathrm{NH}_{3}-\mathrm{N}, \mathrm{TP}$ and $\mathrm{NO}_{3}-\mathrm{N}$ were increasing with increase in cycle time from $2 \mathrm{~h}$, by $0.55,17.05,3.45,2.13$ and $57.14 \%$ respectively for $4 \mathrm{~h}$ cycle time and $1.07,31.82,17.24,6.38$ and $114.29 \%$ respectively for $6 \mathrm{~h}$ cycle time and 1.40,38.64, 25.29, 10.64 and $142.86 \%$ respectively for $8 \mathrm{~h}$. It is evident that increase in cycle time increases the pollutant removal efficiency of the SBR process; however increase in cycle time increases the volume of the SBR and hence the cost of the system, for example for treating $500 \mathrm{~m}^{3} \cdot \mathrm{d}^{-1}$ of dairy wastewater the volume of SBR is $125 \mathrm{~m}^{3}$ (one-fourth of daily flow) for $6 \mathrm{~h}$ cycle time as against $167 \mathrm{~m}^{3}$ (one-third of daily flow) for $8 \mathrm{~h}$ cycle time. Results from the study suggest that the $6 \mathrm{~h}$ cycle time is the optimum cycle time for treating dairy wastewater for simultaneous removal of carbon and nutrient on economical point of view.

\section{Conclusion}

Experimental study on a bench scale Sequencing batch reactor (SBR) model was carried out in a dairy to ascertain it's suitabilty for simultaneous nitrification and denitrification (SNdN) to select optimum cycle time for treating dairy wastewater. Four cycle times of $8 \mathrm{~h}, 6 \mathrm{~h}, 4 \mathrm{~h}$ and $2 \mathrm{~h}$ in SBR were considered in the study. From the study it was found that the SBR process in a single reactor is an efficient process for treating the dairy wastewater for SNdN and achieving effluent with very low nitrogen and phosphorus from a highly concentrated dairy wastewater.. While this study clearly demonstrated SBR process with $6 \mathrm{~h}$ cycle time is optimal for dairy wastewater treatment with better efficiency than existing WWT Plant for nutrient removal, translation of this approach in real time at large scale is yet to be determined.

\section{ACKNOWLEDGEMENTS}

Aavin dairies, Sholinganallur, Chennai, India provided all facilities and permitted to carry out this study in their premises. Their help for the study is gratefully acknowledged.

\section{REFERENCES}

APHA (1998), Standard methods for Examination of Water and Wastewater (Lenore, S. C., Greenberg, A. E., Eaton, A.D., des.), $20^{\text {th }}$ edn. American Public Health association. NW, Washington, DC.

Artan N., Orhon D. and Tusli R. (2002), Design of SBR systems for nutrient removal from wastewaters subject to seasonal fluctuations, Water Sci. Technol., 46(8),91-98.

Artan N. and Orhon D. (2005), Mechanism and design of sequencing batch reactor for nutrient removal, IWA Publishing, London. 
Carta E.F., Mateos A.P., Guzmán R.F. and Marín P.J. (2002), Changes in the Nutrients from a Dairy Wastewater in BatchReactor at high pH and Organic Load, Chem. Biochem. Eng. Q, 16(3), 131-137.

CPCB, Central Pollution Control Board, www.cpcb.nic.in/Industry_Specific_Stan

Coma M., Puig S., Monclús H., Balaguer M.D. and Colprim J. (2010), Effect of cycle changes on simultaneous biological nutrient removal in a sequencing batch reactor (SBR), Environ Technol., 31(3), $285-94$. doi: 10.1080/09593330903464043.

David P.W. (2001), Nitrogen Removal From Dairy Manure Wastewater Using Sequencing Batch Reactors, URN- Etd08082001-103610.

Debik E. and Manav N. (2010), Sequence optimization in a sequencing batch reactor for biological nutrient removal from domestic wastewater, Bioprocess Biosys. Eng., 33(5), 533-540. Doi: 1007/s00449-009-0366-1.

EPA (US Environmental Protection Agency), (2008), Municipal Nutrient Removal Technologies. Reference Document, Vol.I. Technical Report, EPA 832-R-08-006.

Ganesh R., Balaji G. and Ramanujam R.A. (2006), Biodegradation of tannery wastewater using sequencing batch reactor - Respirometric assessment, Bioresource Technology, 97(15), 1815-1821.

Gutierrez M.S., Ferrari A., Benítez A., Hermida S. and Canetti R.M. (2002), Carbon and Nitrogen Removal from Dairy Wastewater in a Laboratory Sequential Batch Reactor System, Water Sci. and Tech., 27(4), 625-633.

Kargi F. and Uygur A. (2003), Nutrient removal performance of a five-step sequencing batch reactor as a function of wastewater composition, Process Biochemistry, 38, 1039-1045.

Keller J., Watts S., Battye-Smith W. and Chong R. (2001), Full scale demonstration of biological nutrient removal in a single tank SBR process, Water Sci. Technol., 43, 355-362.

Ketchum Jr. L.H. (1997), Design and physical features of sequencing batch reactors, Water Sci. and Technol., 35(1), 11-18.

Mahvi A.H. (2008), Sequencing batch reactor- A promising technology in wastewater treatment, Iran.J. Environ. Health. Eng. Sci., 5(2), 79-90.

Metcalf \& Eddy, Inc. (2003), Wastewater Engineering - Treatment and Reuse; Fourth Edition, Tata McGraw-Hill Publishing Company Ltd. New Delhi.

Morishita T. (1985), Environmental hazard of sewage and industrial effluent in irrigated farm lands in Japan, in proceedings FAO Regional Seminar on the treatment and reuse of sewage effluent for irrigation, Nicosia, Cyprus, 7-9.

Munch E.V., Lant P. and Keller J. (1996), Simultaneous nitrification and denitrification in bench scale sequencing batch reactor, Water Res., 30, 277-284.

Norcross K.L. (1992), Sequencing Batch Reactors- An Overview, Wat. Sci. Tech., 26(9), 2523 - 2526.

Obaja D., Mace S., Costa J., Sans C. and Mata A.J. (2003), Nitrification,Denitrification and biological phosphorus removal in piggery wastewater using sequential batch reactor, Bioresource technology, 87(1), 103-111.

Pochanna K. and Keller J. (1999), Study of factors affecting simultaneous nitrification and denitrification (SND), Water Sci. Tech., 39(6), 66-68.

Puig S., Corominas L., Balaguer M.D. and Colprim J. (2007), Biological nutrient removal by applying SBR technology in small wastewater treatment plants: carbon source and C/N/P ratio effects, Water Sci Tech., 55(7), 135-41.

Roe Y.S., Tyagi R.D., Soheible K.C. and Heidman J.A. (1997), Nitrification, denitrification and phosphorous removal in sequencing batch reactor, Bioresources Tech., 61, 151-157.

Sirianuntapiboon S., Jeeyachok N. and Larplai R. (2005), Sequencing batch reactor biofilm system for treatment of milk industry wastewater, J. Environ. Manage., 76, 177-183.

Zhang Pang and Zhau-Qi, (2007), Simultaneous nitrification and denitrification in activated sludge system under low oxygen concentration, Front. Environ. Science Eng. China, 1(1) 49-52. 